\title{
AN EXPERIMENTAL INVESTIGATION OF MEMORY SPAN
}

\section{BY ROY BRENER}

\section{Uniocssity of Chicago*}

The present study is concerned with the relative constancy of the memory span. In the literature there is no definite evidence as to whether memory span is general or specific, i.e., whether the span of an individual remains constant relative to that of the other members of the group in spite of the variations due to the influence of other factors. In this investigation two factors were varied at different times, namely, the type of material and the sensory avenue of presentation. The object was to investigate the constancy of the individual in relation to the group under these two conditions.

At the same time the data also yield information on the absolute constancy of the memory span. In the earlier literature the general belief was that there was a constant absolute size of memory span, i.e., that the size of the span did not vary with the material presented. Blankenship (I), in a recent summary of the literature, presents evidence to prove that the absolute size of the span varies from material to material. The present study lends further evidence to this latter conclusion. It may be noted in passing that should there be an absolute constancy, that is, should the size of the memory span be independent of the type of material then the question of relative constancy would be automatically solved, and memory span would of necessity be general rather than specific.

\section{Plan of the Experiment \\ Materials and Method of Recall}

Tests were constructed with ten different kinds of material. The materials are listed below with explanations as to the procedure followed in constructing the tests.

- The writer wishes to express his appreciation to Dr. H. A. Carr, Dr. F. A. Kingsbury, and Dr. L. L. Thurstone for their guidance and ssoistance during the course of this study. He also wishes to thank Mr. Ledyard R. Tucker for his suggestions of procedure in the factorial analysis on which the latter part of the study is based. 
However, in order to clarify the procedure and the general set-up of the experiment - few words of explanation are given on the terminology used to describe the tests. Each test was composed of a variable number of units. In the digit test, for example, each digit was a unit; in the sentence test each sentence was a unit, etc. The units were organized into series of varying lengths. In some tests the minimum length of a series was one unit; in some tests the maximum length was thirteen units. The presentation of a series to the subject constituted a trial. In all the tests except two each unit was typed on a separate $3^{\prime \prime} \times 5^{\prime \prime}$ card. In the two remaining tests $3^{\prime \prime} \times 5^{\prime \prime}$ cards were also used. However, in one of the tests, the test of Geometrical Designs, each unit was drawn on a card rather than typewritten. In the other test, the test of Colors, each unit was pasted on a separate card.

Digits.-In the digit test, as already indicated, each digit was a unit. Ten series of four units were constructed, ten series of five units, ten series of six units, etc., up to and including ten series of thirteen units. In all other tests, likewise, ten series were constructed for each unit length. In constructing the various series for the digits the usual precautions were observed. An attempt was made to avoid common associations such as historical dates, the current year, etc. No digit was placed next to one immediately following or preceding it in the usual order of counting; e.g., the number seven was never placed after six or eight. No digit was repeated in any one series except where there were more than nine units to the series. The method of recall of the series of digits was oral reproduction. This method of recall was used for all of the tests except the test of Memory for Commissions. At the conclusion of each series the subject was supposed to repeat the digits in the order of their appearance in the series.

Nonsense Syllables.-Each nonsense syllable constituted a unit. Series for this test varied in length from one to six units inclusive. All of the nonsense syllables used in this test were chosen from Glaze's (3) list of syllables having associational values ranging from 40 percent to 53.33 percent. In reproducing any given series the subject was instructed to spell out the three letters of each nonsense syllable rather than to pronounce the syllable.

Consonants.-Each consonant constituted a unit. The series varied in length from four to thirteen units inclusive. In constructing the series the same general rule was followed as for digits, with the additional consideration that no series contained the same unit twice. Likewise, in recall the procedure was the same as for digits.

Geometrical Designs. - The following figures or designs were used: oval, triangle, square, spede, heart, diamond, trapezoid, circle and semi-circle. Each design constituted a unit. The series varied in length from four to nine units inclusive. The designs were drawn in India ink on $3^{\prime \prime} \times 5^{\prime \prime}$ cards. All of the designs were made as nearly equivalent in area as possible. The area per design was approximately one-half square inch. In recalling any series the subject was supposed to repeat the names of the designs in their proper order.

Colors.-The following colors were used: red, orange, yellow, green, blue, white, purple, black and gray. Strips of color one-fourth by one inch were cut from sheets of paper ordinarily used in color vision experiments. Each strip was pasted on a card $3^{\prime \prime} \times 5^{\prime \prime}$ to constitute a unit. The series varied in length from four to ten units inclusive. Again, the subject reproduced orally the names of the colors in the order of their appearance.

Concrete Words.-Each unit was a four letter concrete noun, e.g., gast, hand, doll, etc. The series varied in length from four to ten units inclusive. Special care was taken to avoid alphabetical arrangement of the units and obvious associations such as 
hand, foot, etc. At the conclusion of a series the subject repeated the words in the order of their appearance.

Paired Associates. - The unit was a combination of a three letter concrete noun and a two digit number, e.g., boy-3x. The series varied in length from two to five units inclusive. In recall the subject had to repeat orally the noun and its corresponding number, exch unit in its proper order.

Abstract Words.- The unit consisted of a five, six, or seven letter abstract noun of one or two syllables. In constructing the series for the test the units were chosen so that every series of a given unit length contained exactly the same number of letters and the same number of syllables. For example, each of the ten series of four-unit length contained eight syllables and twenty-four letters; each series of five-unit length contained nine syllables and thirty-two letters, etc. The series varied in length from four to nine units inclusive. The procedure in recall was the same as for conerete words.

Memory for Commissions. - The unit in this test consisted of a simple command. An example of such a unit is the following: "Put a circle around A." Another is: "Put a comma below B." Each unit was five or six words in length. The series varied in length from one to five units inclusive. As mentioned above the method of recall in this test differed from the others. Instead of repeating the commission orally the subject performed the task on a card placed before him for that purpose. As in the other tests, however, each commission was to be performed in the order of its appearance in the series.

Simple Sentences.-In this test a simple declarative sentence constituted 2 unit. Each sentence consisted of six words in eight syllables. An example of a unit is the following: "Mary waved to the cheering crowd." The eeries varied in length from one to five units inclusive. In recalling each series the subject was to repeat each unit, i.e., each sentence, verbatim and in its proper order in the series.

Auditory Tests.-In addition to the ten visual tests listed above, there were also three auditory tests-tests for consonants, concrete words and abstract words. The same procedure was followed in constructing these tests as in constructing the visual tests for the same materials. In fact, the tests were identical except for a rearrangement of the units in the various series. As in the visual tests the method of recall was oral reproduction.

\section{Method of Presentation}

In the visual presentation of the test material to the subject the following procedure was adopted throughout the experiment: the subject sat at a table opposite the experimenter who was hidden from view by a black cloth screen. The cards containing the units of material were shown to the subject through an exposure apparatus at the rate of one card every two seconds. This rate of exposure, two seconds per unit, was maintained throughout the experiment. Since the cards were fed into the exposure apparatus by hand, a special device was set up to assure as accurate timing as possible. An electrically controlled metronome clicking at the rate of once every two seconds was enclosed in a sound box. The sound of the metronome was conducted to the experimenter by a set of ear-phones. The actual experiment was not begun until the experimenter had had sufficient practice in synchronizing the dropping of the card with the clicking of the metronome.

Before the presentation of any series the subject was told how many units the series contained. He was also given a warning signal approrimately one second before the presentation of the first unit of the series. In order to make sure that the same 
exposure time was allowed for the last unit of a series as for the others the subject was told not to repeat the series to the experimenter until the appearance of a blank card after the last unit of the series. For example, if a series consisted of five units, each unit being visible for two seconds, the fifth card was followed by a blank card at an interval of two seconds. Immediately on the appearance of the blank card the subject repeated the entire series. It was further emphasized in the instructions to the subject that in those cases where he could not repeat the entire series he was to give as much of it 28 possible in proper order, indicating the omitted units by saying the word 'Blank.'

The order in which the tests were presented to the subject is the order in which they are listed above. The same order was used for all subjects so that practice effect would be as nearly constant as possible.

In the digit test, which was the first, the subject was given ten series of sir units each. If he got all ten series correct, he was then given ten series of seven units length. If, however, he failed in any of the series of six units length, he was given ten series of five units length, etc., in descending order until the point was reached where all ten series of a given unit length were repeated correctly. The unit length at which all the ten series were given correctly is referred to as the 'basal level.' After the basal level had been established, the subject was then given ten series of each unit length for which he had not yet been tested until the point was reached where he failed all ten trials of a given unit length. An example is herewith given of the order of presentation of the series to Subject B in the digit test. Subject B was given the ten series with six units per series and repeated six of the ten series correctly. He was then given the ten series of five units and responded correctly on eight. Next followed the ten series of four units, on which be repeated all the series correctly. The series of four units length constituted the basal for Subject B. Next followed ten trials of seven units length, four of which were given correctly. Three of the series of eight units length were correct, one of the series of nine units length was correct, and none of the series of ten units length were correct. This concluded the digit test for Subject B.

The same general procedure was followed for all of the visual tests, except the test of memory for commissions. The administration of the auditory tests differed from the visual only in that the material was read by the experimenter. But the rate of presentation, the number of series, the number of units per series, and the mode of response were the same for the auditory and visual tests.

As already mentioned, the only noteworthy deviation from the above procedure was in the test of memory for commissions. Accordingly, the procedure for this test is herewith outlined. A card was placed before the subject on which were printed in ink certain symbols, e.g., the letters $A$ and $B$ or the digits two and three, or combinations of letters and digits. A pencil was placed before the subject along with the card. The subject was then told to attend to the exposure apparatus, and after the usual warning signal, the units of each series, that is, the commissions or the commands, were presented exactly as were the units of every other test. Upon the appearance of the blank card which indicated the close of the series, the subject picked up the pencil and performed the operations on the symbols on the card before him. As in the other tests, there were ten series for each unit length.

The length of time for the completion of a test varied from test to test and from individual to individual. Those tests in which the units were compler, such as the test of Sentences and the test of Memory for Commissions, took a relatively short time, since the subjects failed on all ten series where only three or four units were involved. Thase tests in which the units were less complex, such as the test for Digits 
and the tests for Consonants, took a longer time. Likewise, subjects who did the best took the longest time. With practically all the subjects the thirteen tests were completed in four or five sessions of about one hour each. In the case of $2 \mathrm{few}$ of the highest scoring subjects a sirth session was required. No limitations were placed on the number of days between sessions, but for each subject the time of day during which the experiment was conducted was held constant within a few hours. In no cases were subjects tested at one time early in the moming and the nert time late in the afternoon.

In the final cxperiment forty subjects were used. All of the subjects were students of the University of Chicago.

\section{Method of Scoring}

Guilford and Dallenbach (4) list twenty-seven methods of scoring tests of memory span. It is obvious that the choice of a method is arbitrary. The feature which determines whether a method is good or not is the degree to which it is capable of distinguishing between subjects.

In the present study the following procedure was used. A series was scored either right or wrong. Every unit of a series had to be repeated by the subject verbatim and in the order in which it was presented in order to earn credit. Any deviation from the above made the series wrong. One-tenth of a point (.r) was given for a correct series. No credit was given for a wrong series. As an initial score, the subject was given the number of points corresponding to the number of units in his basal level. If 2 subject had a basal level of four in a given test, he was given an initial score of four points. One-tenth of a point (.I) was added to the initial score for every correct response thereafter. The sum total of the initial score plus the credit for the correct responses above the basal level constituted the subject's score for that particular test.

Below is given the score of Subject B, mentioned above, in the Digit Test.

\begin{tabular}{c|c|c|c}
\hline \hline Units per Series & Number of Trials & Number Correct & Score \\
\hline 4 & 10 & 10 & 4.0 \\
5 & 10 & 8 & .8 \\
6 & 10 & 6 & .6 \\
7 & 10 & 4 & .4 \\
8 & 10 & 3 & .3 \\
9 & 10 & 1 & .1 \\
10 & 10 & 0 & .0 \\
\hline
\end{tabular}

Total Score. ........................... 6.2

Scores for each subject in all thirteen tests were obtained in the seme way.

As stated above, series were scored either right or wrong. No credit was given for partially correct responses. However, in view of the fact that the subjects were instructed to repeat as many units as they could in a given series even though they knew part of the series was wrong, it was felt that a score based on credit for partially correct responses might yield some interesting results. Accordingly, four of the tests were scored in this additional way with credit being given for partially correct responses. The four tests thus bcored were Nonsense Syllables, Paired Associates, Memory for Commissions, and Sentences.

In the test of Nonsense Syllables each syllable contained three letters. By the second method of scoring the subject was given one point for each letter correctly repeated. In a series of two units the subject could make a maximum score of six 
points. If one letter in such a series were missed, the subject was given a score of five points, if two letters were missed, four points, etc. It should be noted that not all of the subjects were tested on the same number of series. Some of the subjects missed all ten series of four-unit length and were not tested on the series of five-unit length. Therefore in scoring by the second method it was important that only those series be included in which every subject had been tested. The same precaution was followed in scoring the other three tests.

In the test of Paired Associates each unit gave a maximum score of two pointsone for the word and one for the number accompanying it. For example, if for the unit, 'boy-31,' the subject said, 'boy-32' or 'man-31,' he was given only one point for the unit. In a two-unit series the maximum score was four points; in 2 three-unit series sir points, etc.

In the test of Memory for Commissions each unit was given a maximum value of three points-one for each operation involved in the unit. For example, in the command, "Put a comma under A," the subject had three operations to bear in mind. One was the use of the correct operational symbol. The subject could have used a colon or a plus sign or a minus sign instead of 2 comma. He also had to remember the position of the operational symbol, since he could have placed it above, beside, or in the letter rather than below it. Finally, he had to remember the letter on which the operation was to be performed. He could have put the comma below B or C instead of below A. He was therefore given one point for each of these correct operations, or a maximum of three points per unit.

In the test of Sentences each unit was given a maximum value of six points-one point for each word in the sentence. A two-unit series gave a maximum score of twelve points; a three-unit series, a maximum value of eighteen points, etc.

In each of these four tests the final score was the total number of points earned.

\section{RESULTS AND INTERPRETATION}

The data yield information on the comparative magnitude of the memory span for the different materials and for the two sensory avenues, the visual and the auditory.

Table I contains the mean score for each of the seventeen tests, the standard deviations of the scores, and the standard errors of the means.

It should be noted that the tests numbered from fourteen to seventeen inclusive are not comparable to the first thirteen in terms of actual size of span, since the first thirteen tests were scored in terms of units and the remaining four in terms of the number of parts in each unit.

Differences in memory span for different kinds of material were reported by Calhoon (2), Lumley and Calhoon (5), Squire (6), Warden (II), and others. In no case, however, were the conditions of the experiments similar enough to justify a direct comparison of actual figures representing the 
TABLE I

Table of Mean Raw Scores and Varubility gor Ence Typi of Matrerhl

\begin{tabular}{|c|c|c|c|}
\hline Teat & Mean & - & $\begin{array}{c}\text { Standard } \\
\text { Error of } \\
\text { Mean }\end{array}$ \\
\hline 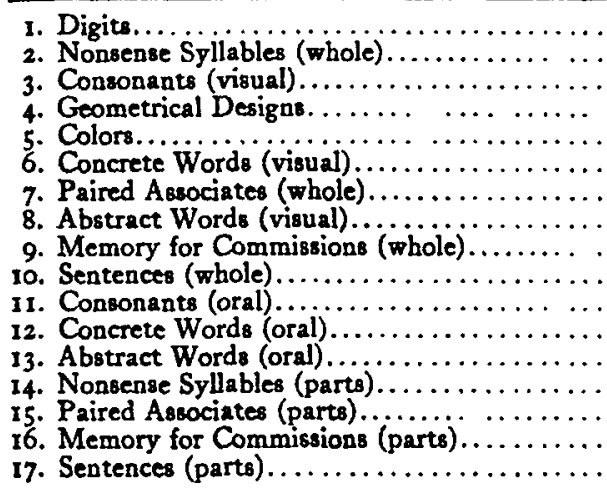 & $\begin{array}{r}7.98 \\
2.49 \\
7.30 \\
5.31 \\
7.06 \\
5.76 \\
2.50 \\
5.24 \\
2.42 \\
1.75 \\
7.21 \\
5.86 \\
5.58 \\
203.85 \\
125.40 \\
192.60 \\
275.90\end{array}$ & $\begin{array}{r}1.112 \\
.353 \\
1.200 \\
1.010 \\
1.130 \\
.876 \\
.804 \\
.763 \\
.343 \\
.320 \\
1.065 \\
.807 \\
.811 \\
28.390 \\
18.830 \\
25.590 \\
30.990\end{array}$ & $\begin{array}{l}.176 \\
.056 \\
.190 \\
.160 \\
.179 \\
.139 \\
.127 \\
.121 \\
.054 \\
.051 \\
.168 \\
.128 \\
.128 \\
4.172 \\
2.977 \\
4.046 \\
4.900\end{array}$ \\
\hline
\end{tabular}

spans for different kinds of materials. Among the factors that varied from experiment to experiment were the ages of the subjects, the length of time of exposure of the material, method of presentation, method of measuring retention, method of scoring, etc. Blankenship (1), on the basis of a survey of the literature, reports the order of difficulty to be nonsense syllables, letters, digits, and finally sentences and related words. A survey of Table I shows that digits seem to be the easiest to remember, with consonants and colors next in order, there being little difference between consonants and colors. Following are concrete words, geometrical designs, and abstract words. No clear differentiation should be made in the order of difficulty of the latter three. The differences between them are not great, and it is not at all unlikely that if the concrete words were made a little longer, or the geometrical designs a little simpler, the order would be reversed. The same holds true for abstract words and geometrical designs, and for abstract words and concrete words.

The last group, the most difficult, are paired associates, nonsense syllables, memory for commissions, and simple sentences. Again, as in the previous group, no definite order of 
difficulty should be indicated, since slight changes in the difficulty of the units involved would change the order.

It may be noted that if a nonsense syllable is considered as a group of three letters rather than as a single unit, the mean score becomes 8.47 ( $3 \times 2.49$-which is the score for nonsense syllables treated as a unit) as compared to 7.30 which is the mean score of consonants. One possible explanation for this difference in mean scores is the fact that the middle letter of each nonsense syllable is a vowel. Since the choice of vowels is more limited than the choice of consonants, the chance of error is accordingly less. Likewise, multiplying the mean sentence score. by six (which is the number of words per sentence) gives a mean score of 10.50 for meaningfully grouped words as compared to a mean score of 5.76 , the score for concrete words presented singly. On the other hand, attention should be called to the fact that the difference between grouped letters and single letters and between grouped words and single words is complicated by the difference in length of exposure time. In the case of single letters the total time of exposure of three letters was six seconds. In the case of grouped letters (nonsense syllables) the total time of exposure was two seconds. Also, in the case of discrete concrete words the total time of exposure of six words was twelve seconds. In the grouped series of words, i.e., in the sentences, the time of exposure for six words was two seconds.

Finally, a comparison can be made between the two different sensory avenues. Table I shows that there is no significant difference between consonants presented visually and orally, or between concrete words presented visually and orally, and that there is only a slight difference between abstract words presented visually and orally.

The second question to be considered is the generality or specificity of the memory span, i.e., the constancy of the span of an individual in relation to the members of the group, where the only variable manipulated is the kind of material in the various tests or the sensory avenue of presentation. As will be shown in further consideration of the results, the question of the relative constancy of the span of the individual or of the 
generality or specificity of the span is intimately tied up with the question of the number of separate abilities called for by all of the tests of the battery.

If there is only one general memory span factor involved, that is, if the individual's relative position in the group depends entirely on one ability that is called for in all of the tests and is not influenced by the type of material on which the span is tested, we would expect the distribution of the mean standard scores for all subjects to be fairly well scattered from high positive to high negative values. Likewise, we would expect any subject to have approximately the same standard score on all tests, with little variability in the score. Conversely, if the influence of a general memory span factor were negligible, and the individual's position in the group is dependent on separate abilities called for by the different tests, we would expect the distribution of the mean standard scores for all of the subjects to cluster around zero. We would further expect a widely scattered group of standard scores for any one subject. In the limiting case where there would be no correlation between the different scores the standard deviation would tend to approach the limiting value of 1.00, and the standard error of the standard scores of the subject would tend to approach the limiting value of .171. (Substituting in the formula

$$
\sigma_{e}=\frac{\sigma \text { distribution }}{\overline{2 N}},
$$

where $N$ is 17 , as in this case, the limiting value would be .17r.)

An examination of Table 2 shows that a point in between the two suppositions mentioned above is approximated. The distribution of the means of the standard scores is fairly wide, ranging from $-1.31 \sigma$ to $+1.77 \sigma$. Further, on examination of the means and sigmas for each subject, it is seen that the standard deviation of the standard scores range from .363 to .799 with an average for all forty subjects of $.53 \mathrm{I}$, and that the standard error of the standard scores ranges from .050 to .13 I with an average for all forty subjects of .ogr.

The above results suggest the conclusion that all of the tests call for a common ability, thus tending to keep the posi- 
tion of the individual constant in relation to the rest of the group, but also that certain abilities are called for in some of the tests and not in others, thus tending to make the position of the individual fluctuate in relation to the rest of the group.

A factorial analysis of the table of intercorrelations of the tests tends to bear out this conclusion.

TABLE 2

Table of Mean Standard Scores and Varlabiltty por ald Subjects

\begin{tabular}{c|c|c|c|c|c|c|c}
\hline \hline Subject & $\begin{array}{c}\text { Mean } \\
\text { Standard } \\
\text { Score }\end{array}$ & $\begin{array}{c}\text { Distribu- } \\
\text { tion }\end{array}$ & $\sigma_{*}$ & Subject & $\begin{array}{c}\text { Mean } \\
\text { Standard } \\
\text { Score }\end{array}$ & $\begin{array}{c}\text { of of } \\
\text { Ditribu- } \\
\text { tion }\end{array}$ & $\sigma_{\sigma}$ \\
\hline 1 & .97 & .607 & .104 & 21 & 1.38 & .604 & .103 \\
2 & -1.31 & .749 & .128 & 22 & .73 & .446 & .076 \\
3 & -1.77 & .553 & .095 & 23 & -.40 & .700 & .120 \\
4 & -1.31 & .543 & .093 & 24 & 1.00 & .428 & .073 \\
5 & -.09 & .569 & .098 & 25 & .45 & .456 & .078 \\
6 & -.62 & .551 & .094 & 26 & .06 & .393 & .067 \\
7 & -.12 & .602 & .103 & 27 & -.83 & .799 & .137 \\
8 & -.15 & .566 & .097 & 28 & -.09 & .477 & .082 \\
9 & .96 & .428 & .073 & 29 & -.01 & .630 & .108 \\
10 & -.72 & .462 & .079 & 30 & 1.23 & .612 & .105 \\
11 & .66 & .390 & .067 & 31 & -1.00 & .651 & .112 \\
12 & .12 & .598 & .103 & 32 & -1.24 & .476 & .082 \\
13 & .39 & .516 & .089 & 33 & -.74 & .468 & .080 \\
14 & -.30 & .427 & .073 & 34 & 1.14 & .651 & .112 \\
15 & -.44 & .747 & .126 & 35 & -.49 & .451 & .077 \\
16 & .07 & .514 & .088 & 36 & -.87 & .587 & .101 \\
17 & .97 & .363 & .062 & 37 & .47 & .542 & .093 \\
18 & .20 & .364 & .062 & 38 & .92 & .434 & .074 \\
19 & -.41 & .402 & .069 & 39 & -.75 & .609 & .104 \\
20 & -.92 & .516 & .089 & 40 & -.86 & .390 & .067 \\
\hline
\end{tabular}

Factorial Analysis

Table 3 contains the intercorrelations of all of the tests. The intercorrelations were computed from the standard scores by the method of rank differences. The correlation matrix was factored by the centroid method, giving the centroid matrix of Table 4. Rotational procedure was then applied to the centroid matrix maximizing the number of zero or near zero projections on the several planes. Table 5 contains the transformation matrix by means of which the rotated factorial matrix of Table 6 was obtained from the centroid matrix. Table 7 shows the correlations between the final primary abilities. 
TABLE 3

TABLE of INTERCorrelation of tae Tests

\begin{tabular}{|c|c|c|c|c|c|c|c|c|c|c|c|c|c|c|c|c|c|}
\hline & $\overrightarrow{\underline{t}}$ & 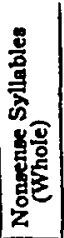 & 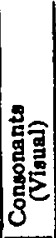 & 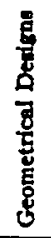 & $\frac{8}{8}$ & 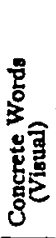 & 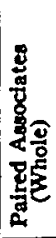 & 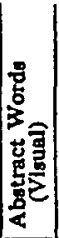 & 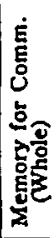 & 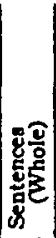 & 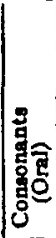 & 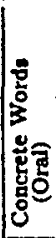 & 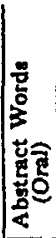 & 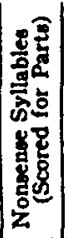 & 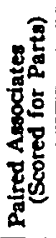 & 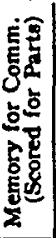 & 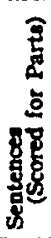 \\
\hline & $\bar{I}$ & 2 & 3 & 4 & 5 & 6 & 7 & 8 & 9 & 10 & II & 12 & 13 & 14 & 15 & 16 & 17 \\
\hline 1 & - & .71 & .88 & & .71 & .69 & .71 & .66 & 40 & & .86 & & .71 & .60 & .69 & 48 & \\
\hline 2 & .71 & 2 & .77 & 5 & .77 & .72 & .79 & .78 & .67 & .71 & .80 & .76 & .75 & .61 & .88 & .59 & .64 \\
\hline 3 & .88 & .77 & & .80 & .86 & .82 & .76 & .77 & .56 & .54 & .87 & 1.75 & .75 & .67 & .74 & .53 & .57 \\
\hline & .74 & .65 & .80 & - & .85 & .72 & .82 & .78 & .52 & .49 & .77 & .62 & .69 & .75 & $6 i$ & .56 & .60 \\
\hline & .71 & .77 & .86 & .85 & - & $.8 \mathrm{I}$ & .83 & .84 & .64 & .57 & .74 & 1.70 & .69 & .78 & .72 & .63 & .69 \\
\hline & .6 & .72 & 8 & .72 & .81 & & .76 & .8 & .65 & .67 & .77 & .83 & .83 & .63 & .72 & .50 & .69 \\
\hline & -71 & .79 & .76 & .82 & .83 & .76 & $\bar{x}$ & .86 & .5 & 0 & .79 & .68 & 80 & .86 & .71 & .56 & .69 \\
\hline & 6 & .79 & .77 & .78 & .8 & .8 & .86 & & .66 & 66 & .80 & .82 & 6 & .80 & .73 & .54 & .73 \\
\hline 0 & .40 & .67 & .56 & .52 & .6 & .65 & .56 & .66 & - & 5 & .57 & .62 & $.6 \mathrm{x}$ & .59 & .62 & 7 & .65 \\
\hline 10 & .54 & $.7 \mathrm{I}$ & .54 & .49 & .57 & .67 & .60 & .6 & .65 & - & .61 & .71 & .72 & .49 & .53 & .49 & .80 \\
\hline 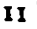 & .86 & .80 & .87 & .77 & .74 & .77 & .79 & 8 & .57 & .61 & - & .82 & 85 & .70 & .7 & & .56 \\
\hline 12 & .73 & .76 & .75 & .62 & 1 & .8 & .68 & 0 & .62 & $.7 \mathrm{I}$ & .82 & & .87 & .58 & .75 & .45 & 70 \\
\hline 13 & .71 & .75 & .75 & .69 & 60 & 8 & .80 & .8 & $.6 \mathrm{I}$ & .72 & .85 & .87 & $1-$ & .70 & .73 & & .63 \\
\hline$I_{4}$ & $.6 c$ & .61 & .67 & .75 & $.7^{8}$ & .6 & .86 & .80 & .59 & .49 & .70 & .58 & 1.70 & & .57 & & .65 \\
\hline 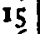 & .69 & .88 & .74 & .61 & .72 & .7 & $.7 I$ & .73 & .62 & .53 & .74 & .75 & .73 & .57 & & .64 & -48 \\
\hline 16 & .48 & .59 & .53 & .56 & 62 & 58 & .56 & .54 & .74 & .49 & .57 & .45 & .52 & .64 & .64 & & .59 \\
\hline 17 & .53 & .6 & .57 & .60 & & & & .73 & .65 & & .56 & .60 & .63 & .65 & $\cdot 4^{8}$ & .59 & \\
\hline
\end{tabular}

TABLE 4

Centroid Matrix

\begin{tabular}{|c|c|c|c|c|c|c|}
\hline & I & II & III & IV & $\mathbf{v}$ & $h^{3}$ \\
\hline I & .811 & .298 & -.051 & .097 & .272 & .833 \\
\hline 2 & .880 & .061 & -.228 & .079 & .041 & .848 \\
\hline 3 & .882 & .290 & .044 & .133 & .163 & .908 \\
\hline 4 & .833 &.$I_{4}$ & .285 &.$\times 52$ & .072 & .816 \\
\hline 5 & .893 & .041 & .270 & .136 & .032 & .892 \\
\hline 6 & .883 & . I10 & .048 & -.230 & -.064 & .851 \\
\hline 7 & .890 & .063 & .242 & .058 & -.069 & $.8 \bar{\sigma}_{3}$ \\
\hline 8 & .917 & .050 & .158 & -.170 & -.180 & .930 \\
\hline 9 & .736 & -.395 & -.140 & .041 & -.155 & .743 \\
\hline 10 & $.74 S$ & -.269 & -.176 & -.332 & .207 & .811 \\
\hline II & .894 & $.23 I$ & -.134 & .067 & .062 & .879 \\
\hline 12 & .857 & .155 & -.223 & -.275 & -.058 & .887 \\
\hline 13 & .886 & .095 & -.114 & -.217 & -.150 & .877 \\
\hline 14 & .809 & -.107 & .293 & .143 & -.168 & .873 \\
\hline 15 & .827 & .147 & -.276 & .170 & -.174 & $.84 \mathrm{r}$ \\
\hline 16 & .687 & -.380 & -.099 & .368 & -.114 & .775 \\
\hline 17 & .768 & -.391 & .150 & -.231 & .197 & .857 \\
\hline
\end{tabular}


TABLE 5

Traneforacation Matrix

\begin{tabular}{c|c|c|c|c}
\hline & A & B & C & \multicolumn{1}{c}{ D } \\
\hline II & .168 & .212 & .191 & .925 \\
III & -.833 & .040 & -.453 & .304 \\
IV & -.316 & .975 & -.099 & -.216 \\
& .422 & .040 & -.865 & .069 \\
\hline
\end{tabular}

TABLE 6

Rotated Factorial Matrux

\begin{tabular}{l|r|r|r|r|r}
\hline & \multicolumn{1}{|c|}{$\mathrm{A}$} & \multicolumn{1}{c|}{$\mathrm{B}$} & $\mathrm{C}$ & $\mathrm{D}$ & $\mathrm{E}$ \\
\hline 1 & -.055 & .138 & -.059 & .858 & .272 \\
2 & .203 & -.030 & .095 & .887 & .041 \\
3 & -.051 & .247 & -.083 & .904 &. .063 \\
4 & .019 & .465 & -.052 & .754 & .072 \\
5 & .088 & .460 & .008 & .790 & .032 \\
6 & -.056 & .229 & .313 & .824 & -.064 \\
7 & .045 & .430 & .068 & .794 & -.069 \\
8 & -.010 & .344 & .284 & .818 & -.180 \\
9 & .514 & .006 & .298 & .594 & -.155 \\
10 & .265 & -.038 & .569 & .622 & .207 \\
11 & .029 & .071 & .022 & .931 & .062 \\
12 & -.031 & -.041 & .354 & .869 & -.058 \\
13 & .014 & .072 & .325 & .858 & -.150 \\
14 & .192 & .459 & .051 & .662 & -.168 \\
15 & .176 & -.081 & -.029 & .881 & -.174 \\
16 & .619 & .049 & -.005 & .567 & -.114 \\
17 & .310 & .284 & .509 & .543 & .197 \\
\hline
\end{tabular}

TABLE 7

Correlations between Prrmary Tratts

\begin{tabular}{c|c|c|c|c}
\hline & A & B & \multicolumn{1}{c|}{ C } & \multicolumn{1}{c}{ D } \\
\hline A & 1.000 & .283 & -.047 & .000 \\
B & .283 & 1.000 & .092 & .000 \\
C & -.047 & .092 & 1.001 & .000 \\
D & .000 & .000 & .000 & 1.000 \\
\hline
\end{tabular}

Attention is called to the column in Table 4 which is called ' $h{ }^{2}$.' This column represents the communality, i.e., that part of the variance of the given test which is due to factors common to other tests in the battery. The reliability of the tests, which is equal to, or greater than, the communality, is high. The variance due to specificity or to error and not accounted for in the extracted factors is correspondingly small. 
Table 5 , the rotated factorial matrix, contains five columns. Each column is interpreted separately.

Column D contains no zero or near zero projections. The smallest projections are for Tests $9,10,16$, and 17, which are the tests of Memory for Commissions and Sentences scored in the two different ways. But even these loadings are fairly high, the lowest being $\cdot 34$. This column represents a general factor. From the nature of the battery it would seem that this factor is the memory span factor.

In Column $C$ the entries to be considered are for the following tests:

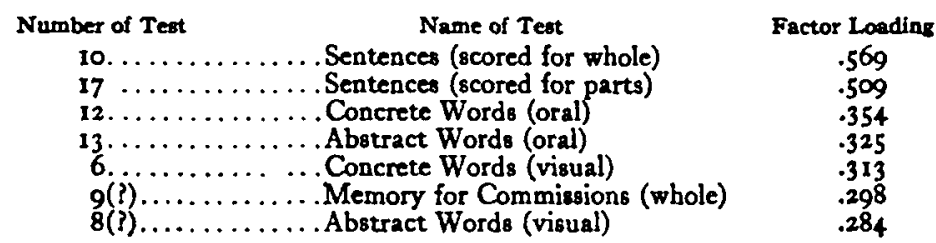

All of the tests with significant entries in Column $\mathrm{C}$ involve words. The tests with the highest loadings (Sentences) certainly involve ideas and words and relationships between words. It is also very possible that the subjects formed relationships or associations even between the discrete abstract and concrete words in an effort to retain them. Accordingly, it is suggested that the factor involved is Thurstone's verbal factor. It should be noted that the battery of tests was not sufficiently large or varied in nature to allow for unquestionable naming or interpreting of the factors. Any suggestions, therefore, in regard to the nature of the factors are highly tentative. These hypotheses or suggestions can be subjected to experimental check-up by including the tests in question in a battery with other tests that are known to be highly saturated with the factor or factors under consideration.

In Column $B$ the entries to be considered are for the following tests:

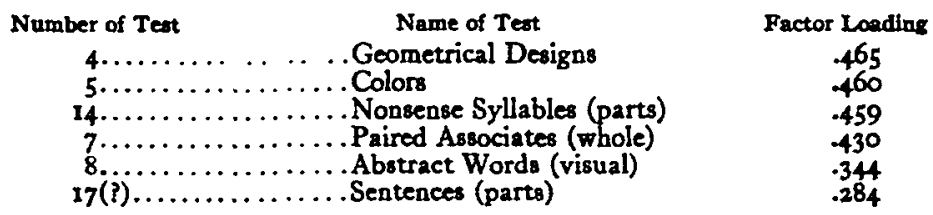


The last one or two factor loadings are rather small, and hence their significance is questionable. It is evident that a factor of visual or spatial imagery may be involved in the tests of Geometrical Designs and Colors. But it is more difficult to explain why it is present in some of the word tests and not in others. However, as indicated before, the nature of the factor may be more readily determined by another experiment with more significant tests added to the battery.

In Column $A$ the entries to be considered are for the following tests:

$\begin{array}{cc}\text { Number of Teat } & \text { Fame of Test } \\ 16 \ldots \ldots \ldots \ldots \ldots \text { Memory for Commissions (parts) } & .619 \\ 9 \ldots \ldots \ldots \ldots \ldots \ldots \text { Memory for Commissions (whole) } & .514 \\ 17 \ldots \ldots \ldots \ldots \ldots \text { Sentences (parts) } & .310 \\ 10(?) \ldots \ldots \ldots \ldots \text { Sentences (whole) } & .265\end{array}$

One way in which the above tests differ from the others is that they involve rapid reading and grasping of a complete idea. The factor may be some sort of a speed factor-possibly speed of reading or speed of apprehension. But, as before, the interpretation is tentative and the only concrete suggestion that may be made is that reading speed tests of several types be added to the present battery to test for the above mentioned factor.

The entries in Column $\mathrm{E}$, the residual plane, are too small to be significant, and no special interpretation is necessary.

One other point of interest in the rotated factorial matrix is the comparative factor loadings of the visual and oral tests. These data are summarized in the table below.

\begin{tabular}{|c|c|c|c|c|}
\hline \multirow{2}{*}{ Test } & \multicolumn{4}{|c|}{ Factor Loading } \\
\hline & $\mathbf{A}$ & B & c & D \\
\hline $\begin{array}{l}\text { Consonants (visual) ......... } \\
\text { Consonants (oral) ........... } \\
\text { Concrete Words (visual) } \ldots \\
\text { Concrete Words (oral) } \ldots . . . \\
\text { Abstract Words (visual).... } \\
\text { Abstract Words (oral) ...... }\end{array}$ & $\begin{array}{r}-.051 \\
.029 \\
-.056 \\
-.031 \\
-.010 \\
.014\end{array}$ & $\begin{array}{r}.247 \\
.071 \\
.229 \\
-.041 \\
.344 \\
.072\end{array}$ & $\begin{array}{r}-.083 \\
.022 \\
.313 \\
.354 \\
.284 \\
.325\end{array}$ & $\begin{array}{l}.904 \\
.931 \\
.824 \\
.869 \\
.818 \\
.858\end{array}$ \\
\hline
\end{tabular}

In general, the factor loadings do not differ significantly for the two methods of presentation. In only one case is the 
difference as high as .27. These results lean toward the view that the same factors are involved in auditory and visual memory span and to about the same degree. It is a question, however, how far we may generalize for materials other than the three reported in this study.

On the whole, the factorial analysis has borne out the conclusions drawn on the basis of the earlier statistical analysis. It was suggested before that the battery had a factor common to all of the tests. Factors $A, B$, and $C$ are common only to certain ones.

\section{Summary}

Following is a summary of the conclusions drawn from the investigation described in the foregoing pages.

I. The listing of the materials in terms of increasing difficulty is as follows: Digits, Consonants and Colors (the latter two of about equal difficulty), Concrete Words, Geometrical Designs, and Abstract Words (the latter three of about equal difficulty), Paired Associates, Nonsense Syllables, Memory for Commissions, and Sentences.

2. The position of the individual in relation to the rest of the group is affected by two things-the presence of an ability common to all of the tests, and the presence of certain abilities common only to special groups of tests. The effect of the common factor is to tend to stabilize the position of the individual. The effect of the other several factors is to make the position of the individual fluctuate in relation to the other members of the group.

3. The general factor is tentatively described as the memory span factor. The other factors are not so readily recognizable as the first. The suggestion is made that one of the other factors may be Thurstone's verbal factor. In the case of the other two factors it is suggested that several kinds of tests of visual imagery and several kinds of tests of reading speed be included in a subsequent battery as a possible means of identifying the other two factors. In all cases, however, it should be clearly noted that the naming or describing of the factors is highly tentative and is intended only as a suggestion of further possible experimental study. 
4. In the case of the three tests presented visually and orally the two methods of presentation seem to involve the same factors to the same degree.

\section{(Manuscript received November 10, 1939)}

\section{References}

I. Brankensaip, A. B., Memory span: a review of the literature, Psychol. Bull., $1938,35,1-25$.

2. Calnoon, S. W., Influence of syllabic length and rate of auditory presentation on ability to reproduce word lists, $J$. exper. Psychol., 1935, 18, 621-632.

3. Graze, J. A., The association value of non-sense syllables, J. genet. Psychol., 1928, 35, 255-262.

4. Guilford, J. P., and Dallenrach, K. M., The determination of memory span by the method of constant stimuli, Amer. J. Psychol., 1925, 36, 621-628.

5. LUsuey, F. H., aNo Calnoon, S. W., Memory span for words presented auditorially, J. App. Psychol., 1934, 18, 773-784.

6. Souire, C. R., Graded mental tests, J. Educ. Psychol., 1912, 3, 363-380.

7. Trunstone, L. L., The Pectors of Mind, Chicago: University of Chicago Press, 1935.

8. Thurstonz, L. L., A new rotational method in factor analysis, Psychometrika, 1938, 3, No. 4.

9. Trurstone, L. L., Primary Mental Abilities, Psychometric monograph, x. Chicago: University of Chicago Press, 1938.

10. Tucker, L. R., A method for finding the inverse of a matrix, Psychometrika, 1938, 3, No. 3 .

11. WARDEN, C. J., The factor of movement in the presentation of rote memory material, Amer. J. Psychol., 1926, 37, 257-260. 